\title{
Combined use of apatinib mesylate and vinorelbine versus vinorelbine alone in recurrent or metastatic triple-negative breast cancer: study protocol for a randomized controlled clinical trial
}

\author{
Shuo $\mathrm{Wu}^{1}$, Liang Zhang ${ }^{1}$, Huan $\mathrm{Li}^{1}$, Junnan $\mathrm{Xu}^{1}$, Cui Jiang ${ }^{1}$ and Tao Sun ${ }^{1,2^{*}}$ (D)
}

\begin{abstract}
Background: The emergence of new molecular targeted drugs provides new prospects for the treatment of advanced breast cancer; the future therapeutic trend includes chemotherapy combined with molecular targeted therapy. Apatinib mesylate, a novel, small anti-angiogenic agent, highly selectively inhibits the activity of vascular endothelial growth factor receptor-2 tyrosine kinase. Apatinib mesylate also blocks the signaling of vascular endothelial growth factor binding to its receptor, thereby strongly inhibiting tumor angiogenesis and exerting an anti-tumor effect. However, there have been no reports of a randomized controlled clinical trial of apatinib combined with vinorelbine for the treatment of triple-negative breast cancer (TNBC). We will compare the therapeutic effect of vinorelbine alone or in combination with apatinib mesylate, in patients with recurrent or metastatic TNBC in North China who have received at least two drug treatments, including anthracyclines and taxanes.
\end{abstract}

Methods/analysis: This study is a triple-blind, randomized, placebo-controlled, parallel-group clinical trial. We plan to include 238 female patients with locally recurrent or metastatic TNBC, admitted to the Liaoning Cancer Hospital \& Institute, Northeast China. All enrolled patients will be randomized to oral vinorelbine alone (40 mg, thrice a week (Mondays, Wednesdays, and Fridays) in each 3-week cycle), or in combination with oral apatinib mesylate (500 mg, once daily in each 3-week cycle). Radiographic assessment will be performed every 6 weeks for 36 weeks and every 9 weeks thereafter. The primary outcome is progression-free survival and secondary outcomes include overall survival, disease control rate, objective response rate, and incidence of adverse events at grades 3 and 4, as defined by the National Cancer Institute Common Toxicity Criteria Version 4.0. Outcome measures will be evaluated at baseline ( $<2$ weeks before starting treatment), every 6 weeks during treatment, and at 4 weeks and every 3 months after treatment discontinuation.

(Continued on next page)

\footnotetext{
* Correspondence: jianong@126.com

'Department of Medical Oncology, Cancer Hospital of China Medical

University, Liaoning Cancer Hospital Institute, Shenyang 110042, Liaoning

Province, China. 2 Key Laboratory of Liaoning Breast Cancer Research, Cancer

Hospital of China Medical University, Liaoning Cancer Hospital Institute,

Shenyang 110042, Liaoning Province, China, Shenyang 110042, Liaoning

Province, China
}

(c) The Author(s). 2020 Open Access This article is licensed under a Creative Commons Attribution 4.0 International License, which permits use, sharing, adaptation, distribution and reproduction in any medium or format, as long as you give appropriate credit to the original author(s) and the source, provide a link to the Creative Commons licence, and indicate if changes were made. The images or other third party material in this article are included in the article's Creative Commons licence, unless indicated otherwise in a credit line to the material. If material is not included in the article's Creative Commons licence and your intended use is not permitted by statutory regulation or exceeds the permitted use, you will need to obtain permission directly from the copyright holder. To view a copy of this licence, visit http://creativecommons.org/licenses/by/4.0/. The Creative Commons Public Domain Dedication waiver (http://creativecommons.org/publicdomain/zero/1.0/) applies to the data made available in this article, unless otherwise stated in a credit line to the data. 
(Continued from previous page)

Discussion: Based on the data from this trial, we hope to identify a treatment plan that is suitable for female patients with TNBC, who have been treated with anthracyclines and taxanes, in Northeast China.

Trial registration: ClinicalTrials.gov: NCT03932526. Registered on 30 April 2019.

Keywords: Triple-negative breast cancer, Apatinib, Vinorelbine, Advanced breast cancer, Metastatic

\section{Introduction}

\section{Background}

The International Agency for Research on Cancer predicts that the number of cancers in the future will increase at an annual rate of $3-5 \%$. The incidence of cancer in low-income and middle-income countries is extremely higher than that in developed countries [1]. Breast cancer is one of the most highly prevalent malignant tumors, with approximately 13 million people newly diagnosed each year. With a mortality rate of 20$30 \%$, breast cancer is a common cause of death among women, accounting for 400,000 deaths annually. In developing countries, breast cancer has become the leading cause of death in women [2].

Triple-negative breast cancer (TNBC) is a subtype of breast cancer with an absence of estrogen receptors (ER), progesterone receptors (PR), and human epidermal growth factor receptor 2 (HER-2). It accounts for 10-17\% of all breast cancers [3], and is characterized by high heterogeneity, high invasiveness, low survival rate, early recurrence, and metastasis. There is a lack of effective treatment for TNBC, and the prognosis is poor [4, 5].

Despite significant advances in breast cancer treatment, approximately $15 \%$ of patients are diagnosed at an advanced stage of breast cancer. According to staging, grading, and choice of treatment, $20-80 \%$ of all patients with invasive breast cancer will eventually relapse and require subsequent treatment [6]. Chemotherapy is the main treatment for early and advanced breast cancer, and the most effective drugs include anthracyclines and taxanes [7]. However, the increasing use of anthracyclines and taxanes in the early stage of the disease makes the choice of a second-line therapy difficult, and drug resistance often limits the choice of treatment regimens [8]. Endocrine therapy, anti-HER-2 targeted therapy, and chemotherapy cannot achieve satisfactory outcomes in $\mathrm{TNBC}$, as there is no corresponding hormone receptor or HER-2 expression.

Some progress has been made in the field of TNBC therapy with the use of immunological checkpoint inhibitors. PD-1 or PD-L1 monoclonal antibody, the most common immunological checkpoint inhibitor, which targets either PD-1 or PD-L1, can block this binding and boost the immune response against cancer cells. Currently, only PD-L1 monoclonal antibody - atezolizumab (Tecentriq ${ }^{\circ}$ ) and PD-1 monoclonal antibody - pembrolizumab (Keytruda) have been approved for use by the US Food and Drug Administration (FDA). The combination of pembrolizumab plus chemotherapy as a neoadjuvant therapy for early TNBC can significantly improve pathologic complete remission [9]. Relative to chemotherapy, pembrolizumab is used as a second-line or third-line treatment for patients with metastatic TNBC, but it does not significantly improve overall survival (OS) [10].

Results from the IMpassion130 trial (a clinical, phase III, double-blind randomized trial reported in 2016 [11], with data updated in 2019 [12]) indicated that the combination of atezolizumab and albumin paclitaxel as a first-line treatment for advanced TNBC yielded better progressionfree survival than the use of paclitaxel plus placebo.

Unfortunately, no approval has been given for clinical trials on checkpoint inhibitors for TNBC in China; furthermore, no such drug is available in clinical practice. Therefore, this study was designed to determine the effect of the combination of apatinib (a small-molecule, antiangiogenic targeted drug) and vinorelbine (a semisynthetic, vinblastine alkaloid antineoplastic drug), two types of drugs that have been used clinically in China, in the treatment of TNBC.

Combination chemotherapy with vascular endothelial growth factor (VEGF) and VEGF receptor (VEGFR) target inhibitors is one of the most promising regimens for advanced breast cancer [13]. Apatinib mesylate (Aitan) is a novel, small anti-angiogenic agent that highly selectively inhibits the activity of VEGFR-2 tyrosine kinase, and blocks the signaling of VEGF binding to its receptor. Thus, it strongly inhibits tumor angiogenesis and exerts anti-tumor effects. While the clinical use of apatinib in breast cancer has been reported, the relevant research has focused mainly on its safety and efficacy in breast cancer expressing different receptors $[13,14]$. The administration of apatinib in patients with $\mathrm{TNBC}$, at an initial dose of $750 \mathrm{mg} /$ day, resulted in mean progression-free survival (mPFS) and mean OS (mOS) of 4.6 and 8.3 months, respectively. A smaller dose $(500 \mathrm{mg} /$ day) resulted in mPFS and $\mathrm{mOS}$ of 3.3 and 10.6 months, respectively [14]. In cases of advanced breast cancer, oral apatinib was used after first-line or second-line treatment failure. The objective response rate (ORR) was $40.0 \%$, the disease control rate (DCR) was $75.0 \%$, and the median time to progression (mTTP) was 12 months [13]. 
Vinorelbine is mainly used for the treatment of nonsmall cell lung cancer and metastatic breast cancer. A previous multicenter clinical trial [15] used vinorelbine combined with cisplatin, capecitabine, or tegafur for the treatment of recurrent and metastatic breast cancer that occurred after treatment with anthracyclines and taxanes. The effective rate was $61.0 \%$, with a complete response (CR) of $4.9 \%$. This combination therapy was highly effective for multiple and single metastatic lesions, and moreover, the therapeutic efficacy was better in multiple metastatic lesions. The short-term effect was fair, with tolerance to toxicity and good safety. Studies have reported the use of vinorelbine combined with 5fluorouracil among patients with advanced metastatic breast cancer (following treatment failure with anthracycline/taxane), and an effective rate of $17.4-46.0 \%$ [1618]. In patients with metastatic TNBC, vinorelbine or gemcitabine combined with cisplatin is preferred after anthracycline/taxane treatment failure. The objective response rates of the experimental group and the control group were $45.45 \%$ and $46.15 \%$, respectively, and the DCRs in the two groups were $77.27 \%$ and $80.77 \%$, respectively. In the experimental group, the time to progression (TTP) was 2.0-18.0 months, and the mTTP was 5.0 months (95\% confidence interval (CI), 3.28-6.72). In the control group, the TTP was $1.8-18.5$ months, with an mTTP of 5.2 months (95\% CI, 3.33-7.07) [19].

\section{Study features and objectives}

While previous cohort studies [13, 20, 21], retrospective observations [22-25], and case reports [26, 27] have addressed the clinical treatment of TNBC with apatinib or vinorelbine (Table 1), there have been no reports of a randomized, controlled clinical trial in North China. As $B R C A$-positive patients would have poor responses to the therapeutic methods designed in this study, $B R C A$ negative female patients with locally recurrent or metastatic TNBC, who have previously received anthracycline and taxane treatment, will be the target population in this trial. We will compare the therapeutic effect of vinorelbine used alone or in combination with apatinib mesylate, for the treatment of recurrent or metastatic TNBC, with the aim of providing clinical evidence for multi-line treatment options.

\section{Methods and analysis \\ Study design}

This study is a triple-blind, randomized, placebocontrolled, parallel-group clinical trial. A sample of 238 female patients with recurrent or metastatic TNBC, who have been pretreated with at least one chemotherapy regimen (including anthracyclines and taxanes), will be recruited. The baseline characteristics, therapeutic schedules, and outcomes of enrolled patients will be documented and reported in accordance with the Consolidated Standards of Reporting Trials (CONSORT) statement [28]. Patient data in each center will be collected by an electronic data capture system.

All enrolled patients will be randomly assigned to receive either oral apatinib mesylate in combination with vinorelbine or oral vinorelbine plus placebo, until disease progression or other criteria indicate the need for the termination of drug administration. A schedule of enrollment, interventions, and assessments is shown in Fig. 1 and a trial flowchart is shown in Fig. 2. The study protocol follows the Standard Protocol Items: Recommendations for Interventional Trials (SPIRIT) guidance for protocol reporting (Additional file 1) [29].

\section{Study participants}

The study participants will be recruited from the Liaoning Cancer Hospital \& Institute in Northeast China.

\section{Inclusion criteria}

The inclusion criteria are:

1. Female patients with recurrent or metastatic TNBC, confirmed by histological or cytological examination.

2. Age $\geq 18$ years.

3. At least one extracranial measurable site of disease according to Response Evaluation Criteria In Solid Tumors (RECIST) version 1.1 criteria [30] and an Eastern Cooperative Oncology Group performance status (ECOG-PS) score of 0-2.

4. Expected survival $\geq 12$ weeks.

5. Tumor hormone receptor status was determined using immunohistochemistry (IHC). Negative for ER/PR: where ER $<1 \%$ indicates positive and PR $<1 \%$ indicates positive. HER2/Neu-negative status was defined as IHC $0-1+$; or Her2/Neu negative by chromogenic/fluorescent in situ hybridization (FISH), according to the Breast cancer HER-2 detection guide (2014 edition) [31]. Further, the insitu hybridization (ISH) method will be used to detect HER-2 gene amplification for further diagnosis.

6. All patients will be tested for bone marrow capacity, liver, and renal function within 7 days prior to enrollment, and will meet the following criteria:

a. Routine blood test: absolute neutrophil (ANC) count $\geq 1.5 \times 10^{9} / \mathrm{L}$; hemoglobin $\geq 9.0 \mathrm{~g} / \mathrm{dL}$; platelet count $\geq 80 \times 10^{9} / \mathrm{L}$;

b. Liver function: total bilirubin $\leq 1.5$ times the upper limit of normal (ULN); alanine aminotransferase (ALT) and aspartate aminotransferase $(\mathrm{AST}) \leq 2.5 \times \mathrm{ULN}$ (patients 
Table 1 Recent clinical studies conducted within the past 5 years on treatment with apatinib or vinorelbine in patients with TNBC pretreated with chemotherapy or radiotherapy

\begin{tabular}{|c|c|c|c|c|c|c|}
\hline Study & Design & Subjects & Assignment & Treatment & Outcome measures & Conclusion \\
\hline \multicolumn{7}{|c|}{ Treatment with apatinib } \\
\hline $\begin{array}{l}\mathrm{Hu} \\
\text { et al. } \\
{[13]}\end{array}$ & $\begin{array}{l}\text { Phase II } \\
\text { cohort study }\end{array}$ & $\begin{array}{l}84 \text { patients previously } \\
\text { treated with anthracycline } \\
\text { and/or taxane: } 25 \text { in } \\
\text { phase lla trial: } 59 \text { in phase } \\
\text { llb trial }\end{array}$ & - & $\begin{array}{l}\text { Phase Ila trial: apatinib, } \\
\text { daily dose of } 750 \mathrm{mg} \\
\text { Phase Ilb trial: apatinib, } \\
\text { daily dose of } 500 \mathrm{mg}\end{array}$ & $\begin{array}{l}\text { ORR and CBR were } 10.7 \% \\
\text { and } 25.0 \% \text {, respectively. } \\
\text { Median PFS and OS were } \\
3.3 \text { and } 10.6 \text { months, } \\
\text { respectively }\end{array}$ & $\begin{array}{l}\text { An apatinib dose of } 500 \\
\text { mg rather than } 750 \text { mg is } \\
\text { the recommended } \\
\text { starting dose for heavily } \\
\text { pretreated patients with } \\
\text { mTNBC with a } \\
\text { measurable rate of partial } \\
\text { response and PFS }\end{array}$ \\
\hline $\begin{array}{l}\text { Li et al. } \\
{[22]}\end{array}$ & $\begin{array}{l}\text { Retrospective } \\
\text { analysis }\end{array}$ & $\begin{array}{l}44 \text { patients with } \\
\text { advanced TNBC with } \\
\text { failed first-line or second- } \\
\text { line therapy }\end{array}$ & $\begin{array}{l}\text { Apatinib + } \\
\text { capecitabine } \\
\text { or } \\
\text { capecitabine } \\
\text { alone }\end{array}$ & $\begin{array}{l}\text { Apatinib (500 mg) was } \\
\text { orally administered daily } \\
\text { on days } 1-28 \text { of each 4- } \\
\text { week cycle and/or cape- } \\
\text { citabine }\left(12,500 \mathrm{mg} / \mathrm{m}^{2}\right) \\
\text { was orally taken twice } \\
\text { daily for } 14 \text { days followed } \\
\text { by a } 7 \text {-day rest period } \\
\text { until disease progression }\end{array}$ & $\begin{array}{l}\text { PFS, ORR (CR + PR), DCR } \\
(C R+P R+S D) \text {, and } \\
\text { toxicity } \\
\text { For apatinib + } \\
\text { capecitabine or } \\
\text { capecitabine alone: PFS, } \\
\text { 5.5, 3.5 months; ORR, } \\
40.9 \%, 13.4 \% \text {; DCR, } 68.2 \% \text {, } \\
31.8 \%\end{array}$ & $\begin{array}{l}\text { Treatment with a } \\
\text { combination of apatinib } \\
\text { and capecitabine can } \\
\text { achieve a better efficacy } \\
\text { and similar rate of serious } \\
\text { adverse events compared } \\
\text { with capecitabine alone, } \\
\text { as the third-line treatment } \\
\text { for advanced TNBC }\end{array}$ \\
\hline $\begin{array}{l}\text { Hu } \\
\text { et al. } \\
{[26]}\end{array}$ & Case report & $\begin{array}{l}\text { A female patient with } \\
\text { stage IV TNBC. She had } \\
\text { previously undergone } \\
\text { whole-brain radiation }\end{array}$ & - & $\begin{array}{l}\text { Treatment with apatinib } \\
+ \text { CPT- } 11+\text { S- } 1 \text { as the } \\
\text { sixth-line therapy }\end{array}$ & $\begin{array}{l}\text { Alleviation of the brain } \\
\text { edema was achieved, } \\
\text { and this was maintained } \\
\text { for } 7 \text { months }\end{array}$ & $\begin{array}{l}\text { Apatinib in combination } \\
\text { with } \mathrm{CPT}-11+\mathrm{S}-1 \text { to treat } \\
\text { refractory BMs in a pa- } \\
\text { tient with TNBC }\end{array}$ \\
\hline
\end{tabular}

After treatment failure Apatinib was more with bevacizumab combined with albuminbound paclitaxel and cisplatin, the patient was treated with apatinib effective than

patient et al.
$[27]$ bevacizumab for this triple-negative spindle cell carcinoma gemcitabine, vinorelbine, and single-agent apatinib were then administere as first-line to fifth-line therapies

Treatment with vinorelbine

\begin{tabular}{|c|c|c|c|c|c|}
\hline $\begin{array}{l}\text { Rodler } \\
\text { et al. } \\
\text { [20] }\end{array}$ & $\begin{array}{l}\text { Phase I } \\
\text { cohort study }\end{array}$ & $\begin{array}{l}50 \text { patients with } \\
\text { advanced TNBC }\end{array}$ & - & $\begin{array}{l}\text { A } 3+3 \text { dose escalation } \\
\text { design evaluated veliparib } \\
\text { and vinorelbine, followed } \\
\text { by veliparib monotherapy }\end{array}$ & $\begin{array}{l}\text { Median PFS in } 50 \\
\text { patients was } 5.5 \text { months }\end{array}$ \\
\hline $\begin{array}{l}\text { Zhang } \\
\text { et al. } \\
\text { [21] }\end{array}$ & $\begin{array}{l}\text { Prospective } \\
\text { cohort study }\end{array}$ & $\begin{array}{l}44 \text { patients with } \\
\text { metastatic TNBC } \\
\text { pretreated with } \\
\text { anthracyclines and/or } \\
\text { taxanes }\end{array}$ & - & $\begin{array}{l}\text { Biweekly combination of } \\
\text { vinorelbine and } \\
\text { oxaliplatin (NVBOX) }\end{array}$ & $\begin{array}{l}\text { ORR } 31.6 \% \text {, median PFS } \\
4.3 \text { months, OS } 12.6 \\
\text { months }\end{array}$ \\
\hline $\begin{array}{l}\text { Wang } \\
\text { et al. } \\
{[23]}\end{array}$ & $\begin{array}{l}\text { Retrospective } \\
\text { analysis }\end{array}$ & $\begin{array}{l}48 \text { female patients with } \\
\text { TNBC }\end{array}$ & - & $\begin{array}{l}\text { Patients were given } \\
\text { vinorelbine plus cisplatin } \\
\text { (NP group, } n=22 \text { ) or } \\
\text { gemcitabine plus cisplatin } \\
\text { (GP group, } n=26 \text { ) }\end{array}$ & $\begin{array}{l}\text { The ORR, DCR, and } \\
\text { median TTP were } 45.5 \% \text {, } \\
77.3 \% \text {, and } 5 \text { months, } \\
\text { respectively, in the NP } \\
\text { group, and } 46.2 \%, 80.8 \% \text {, } \\
\text { and } 5.2 \text { months, } \\
\text { respectively, in the GP } \\
\text { group } \\
\text { A lower incidence of } \\
\text { thrombocytopenia and } \\
\text { rash, and a higher } \\
\text { incidence of phlebitis } \\
\text { was found in the NP }\end{array}$ \\
\hline
\end{tabular}

Apatinib is a safe and effective drug for treating advanced spindle cell breast carcinoma, especially in patients who have a prior experience of chemotherapy failure, or a poor physical condition

Veliparib (300 mg, twice daily) combined with cisplatin and vinorelbine is well-tolerated with encouraging response rates

A biweekly NVBOX regimen is effective and well-tolerated as a second-line or third-line treatment for patients with $\mathrm{MTNBC}$

Both the NP and GP regimens are active and tolerated in cases of metastatic TNBC with anthracycline and/or taxane resistance. These regimens may be used as a salvage treatment for metastatic TNBC 
Table 1 Recent clinical studies conducted within the past 5 years on treatment with apatinib or vinorelbine in patients with TNBC pretreated with chemotherapy or radiotherapy (Continued)

\begin{tabular}{|c|c|c|c|c|c|c|}
\hline Study & Design & Subjects & Assignment & Treatment & Outcome measures & Conclusion \\
\hline & & & & & $\begin{array}{l}\text { group compared to the } \\
\text { GP group }\end{array}$ & \\
\hline $\begin{array}{l}\text { Du } \\
\text { et al. } \\
{[24]}\end{array}$ & $\begin{array}{l}\text { Retrospective } \\
\text { analysis }\end{array}$ & $\begin{array}{l}48 \text { patients with } \\
\text { metastatic TNBC } \\
\text { pretreated with } \\
\text { anthracyclines and one } \\
\text { taxane }\end{array}$ & - & $\begin{array}{l}22 \text { patients were treated } \\
\text { with vinorelbine plus } \\
\text { platinum (NP), and } 26 \\
\text { patients with vinorelbine } \\
\text { plus capecitabine (NX) }\end{array}$ & $\begin{array}{l}\text { Total: ORR, 20.8\%; CBR, } \\
\text { 43.8\%; median PFS, } 4.4 \\
\text { months; median OS, } 15.5 \\
\text { months } \\
\text { ORR and PFS were better } \\
\text { in the NP arm versus NX }\end{array}$ & $\begin{array}{l}\text { Vinorelbine-based } \\
\text { combination } \\
\text { chemotherapy shows } \\
\text { moderate efficacy in the } \\
\text { treatment of metastatic } \\
\text { TNBC, and has } \\
\text { manageable toxicity. The } \\
\text { NP regimen shows } \\
\text { potential superiority over } \\
\text { the NX regimen. }\end{array}$ \\
\hline $\begin{array}{l}\text { Li et al. } \\
{[25]}\end{array}$ & $\begin{array}{l}\text { Retrospective } \\
\text { analysis }\end{array}$ & $\begin{array}{l}41 \text { patients with } \\
\text { advanced TNBC } \\
\text { (pretreated with } \\
\text { anthracyclines and/or } \\
\text { taxanes, before or after } \\
\text { surgery) in whom disease } \\
\text { progressed after a certain } \\
\text { period of time }\end{array}$ & - & $\begin{array}{l}\text { Treatment with } \\
\text { vinorelbine plus platinum } \\
\text { (NP) regimen }\end{array}$ & $\begin{array}{l}\text { ORR, 34.1\%; CR, 7.3\%; } \\
\text { partial response, 26.8\%; } \\
\text { stable disease, 34.1\%; } \\
\text { median OS, } 18.9 \text { months; } \\
\text { PFS, } 6.7 \text { months }\end{array}$ & $\begin{array}{l}\text { The NP regimen showed } \\
\text { clinical activity in patients } \\
\text { with metastatic TNBC, } \\
\text { and the toxicity was } \\
\text { acceptable and } \\
\text { manageable }\end{array}$ \\
\hline
\end{tabular}

PFS median progression-free survival, ORR objective response rate, $D C R$ disease control rate, $B M$ brain metastasis, $T N B C$ triple-negative breast cancer, $C B R$ clinical benefit rate, $O S$ overall survival, $C R$ complete response, $P R$ partial response, $S D$ stable disease, $T T P$ time to progression

with liver metastasis $\leq 5 \times \mathrm{ULN})$; alkaline phosphatase $\leq 4 \times$ ULN;

c. Renal function: serum creatinine $\leq 1.5 \times \mathrm{ULN}$.

7. Previous use of anthracyclines and/or taxanes.

8. The medication history of vinorelbine meets one of the following conditions:

a. No history of, or irregular vinorelbine use (the standard use of vinorelbine is defined based on the appropriate use of the medication as prescribed, for at least two cycles);

b. Patients with advanced breast cancer, who receive a standardized regimen of vinorelbine for 6 months and have no cancer progression; they also have not used vinorelbine within 6 months prior to the first administration.

9. Female patients of childbearing age must take adequate contraceptio, otherwise they must be proven to be infertile, that is:

a. Patients over the age of 50 years are confirmed to have menstruation-deficient menopause for at least 12 months after stopping all exogenous hormone treatments;

b. Under the age of 50 years; on this basis, it is also necessary to prove that the levels of progesterone and follicle stimulating hormone are in the postmenopausal range of the research institution;

c. Women undergoing irreversible sterilization operations (hysterectomy, bilateral oophorectomy, bilateral salpingectomy, etc.) are negative for pregnancy and are not lactating before administration.
10. No history of serious heart, lung, liver, or kidney diseases.

11. Provision of written informed consent.

\section{Exclusion criteria}

The exclusion criteri are:

1. The patients are undergoing current administration of anticancer therapies, or are attending other clinical trials.

2. History or current evidence of brain metastasis, including leptomeningeal involvement.

3. Patients with a BRCA mutation who have poor response to the therapeutic regimen.

4. Patients with severe vascular diseases, including unstable angina, myocardial infarction, or severe arrhythmia in the past 6 months.

5. History of HIV infection or active chronic hepatitis B or C.

6. Patients with other serious infectious diseases.

7. Patients positive for ER/PR/HER-2.

8. Patients with allogeneic organ transplants requiring immunosuppressive therapy.

9. History of other malignant tumors within 5 years, except for cured cervical carcinoma in situ or basal cell carcinoma of the skin.

10. Other destabilizing factors (such as drug abuse and medical, psychological, or social conditions) that may interfere with patient compliance or have an impact on the trial results.

11. Allergy to target drugs or allergy to related drugs applied in the trial.

12. Pregnant or lactating women. 


\begin{tabular}{|c|c|c|c|c|c|}
\hline \multirow[b]{3}{*}{ TIMEPOINT } & \multicolumn{5}{|c|}{ STUDY PERIOD } \\
\hline & \multirow{2}{*}{$\begin{array}{l}\text { Enrolment } \\
-\mathrm{t} 1\end{array}$} & \multirow{2}{*}{$\begin{array}{l}\text { Allocation } \\
0 \\
\end{array}$} & \multicolumn{2}{|c|}{ Post-allocation } & \multirow{2}{*}{$\begin{array}{l}\text { Close-out } \\
\text { t3 } \\
\end{array}$} \\
\hline & & & t1 & t2 & \\
\hline \multicolumn{6}{|l|}{ ENROLMENT: } \\
\hline \multirow{4}{*}{$\begin{array}{l}\text { Eligibility screen } \\
\text { Informed consent } \\
\text { Demographic \& Medical data } \\
\text { Allocation }\end{array}$} & $x$ & & & & \\
\hline & $x$ & & & & \\
\hline & $x$ & & & & \\
\hline & & $x$ & & & \\
\hline \multirow{3}{*}{$\begin{array}{l}\text { INTERVENTIONS*: } \\
\text { Experimental group } \\
\text { Control group }\end{array}$} & & & & & \\
\hline & & $x$ & & & \\
\hline & & $x$ & & & \\
\hline \multicolumn{6}{|l|}{ ASSESSMENTS: } \\
\hline \multirow{4}{*}{$\begin{array}{l}\text { Vital sign } \\
\text { Physical exam } \\
\text { Concomitant medication } \\
\text { ECOG PS }\end{array}$} & $x$ & & $\mathrm{x}$ & $\mathrm{x}$ & \\
\hline & $x$ & & $x$ & $x$ & \\
\hline & $x$ & & $x$ & $\mathrm{x}$ & \\
\hline & $x$ & & $x$ & $x$ & \\
\hline \multirow{2}{*}{$\begin{array}{l}\text { Laboratory examination }{ }^{b} \\
\text { Electrocardiography }\end{array}$} & $x$ & & $\mathrm{x}$ & $x$ & \\
\hline & $x$ & & $x$ & $x$ & \\
\hline \multirow{2}{*}{$\begin{array}{l}\text { Imaging examination } \\
\text { EORTC QLQ-C30 }\end{array}$} & $x$ & & $x$ & $x$ & $x$ \\
\hline & $x$ & & & $x$ & $x$ \\
\hline \multirow[t]{2}{*}{ Response status } & & & $\mathrm{x}$ & $x$ & \\
\hline & & & $x$ & $x$ & \\
\hline Survival status & & & & & $\mathrm{x}$ \\
\hline
\end{tabular}

Fig. 1 Standard Protocol Items: Recommendations for Interventional Trials (SPIRIT). Timepoint (t): -t1: baseline evaluations (conducted within 2 weeks of the start of protocol therapy); t0: random allocation; t1: during treatment (evaluations will be conducted every 6 weeks (two cycles)); $\mathrm{t2}$ : patients will be monitored for new or existing AEs at 4 weeks after treatment discontinuation; t3: follow up for survival will be monitored every 3 months after treatment discontinuation until patient death or study completion. *Eligible patients will be randomly assigned to receive either oral vinorelbine plus placebo (control group) or oral vinorelbine combined with apatinib mesylate (experimental group). ${ }^{\text {a }}$ Concomitant medication includes opioid analgesics and new anticancer treatment. ${ }^{b}$ Laboratory examinations include hematology (hemoglobin, white blood cell count, neutrophil count, and platelet count); blood biochemical tests (total bilirubin, alanine aminotransferase, aspartate aminotransferase, alkaline phosphatase, serum creatinine, total protein, $\mathrm{Na}^{+}, \mathrm{K}^{+}, \mathrm{Mg}^{2+}, \mathrm{Cl}^{-}, \mathrm{Ca}^{2+}$, urea, and pregnancy test (if applicable); and tumor marker detection (breast cancer-associated antigen CA153 and carcinoembryonic antigen). ECOG PS, Eastern Cooperative Oncology Group performance status; EORTC QLQ-C30, the European Organization for Research and Treatment of Cancer Quality of Life Questionnaire Core-30

\section{Recruitment}

Patients will be recruited based on their diagnosis at the Department of Breast Medicine, Liaoning Provincial Cancer Hospital in China, which has a sufficient number of patients with advanced breast cancer. Patients will be screened for eligibility by research staff to ensure all inclusion and exclusion criteria are met. The research staff identifying patients for inclusion into the study will be blinded to the study objectives.

\section{Randomization}

A professional, independent statistician, who will not be involved in the recruitment process of the study, will randomize the participants. The statistician will use the Statistical Analysis System (SAS 9.1) software to generate a randomization sequence list, and assign each patient a serial number. Treatment allocations will be sealed in opaque envelopes prepared by research 


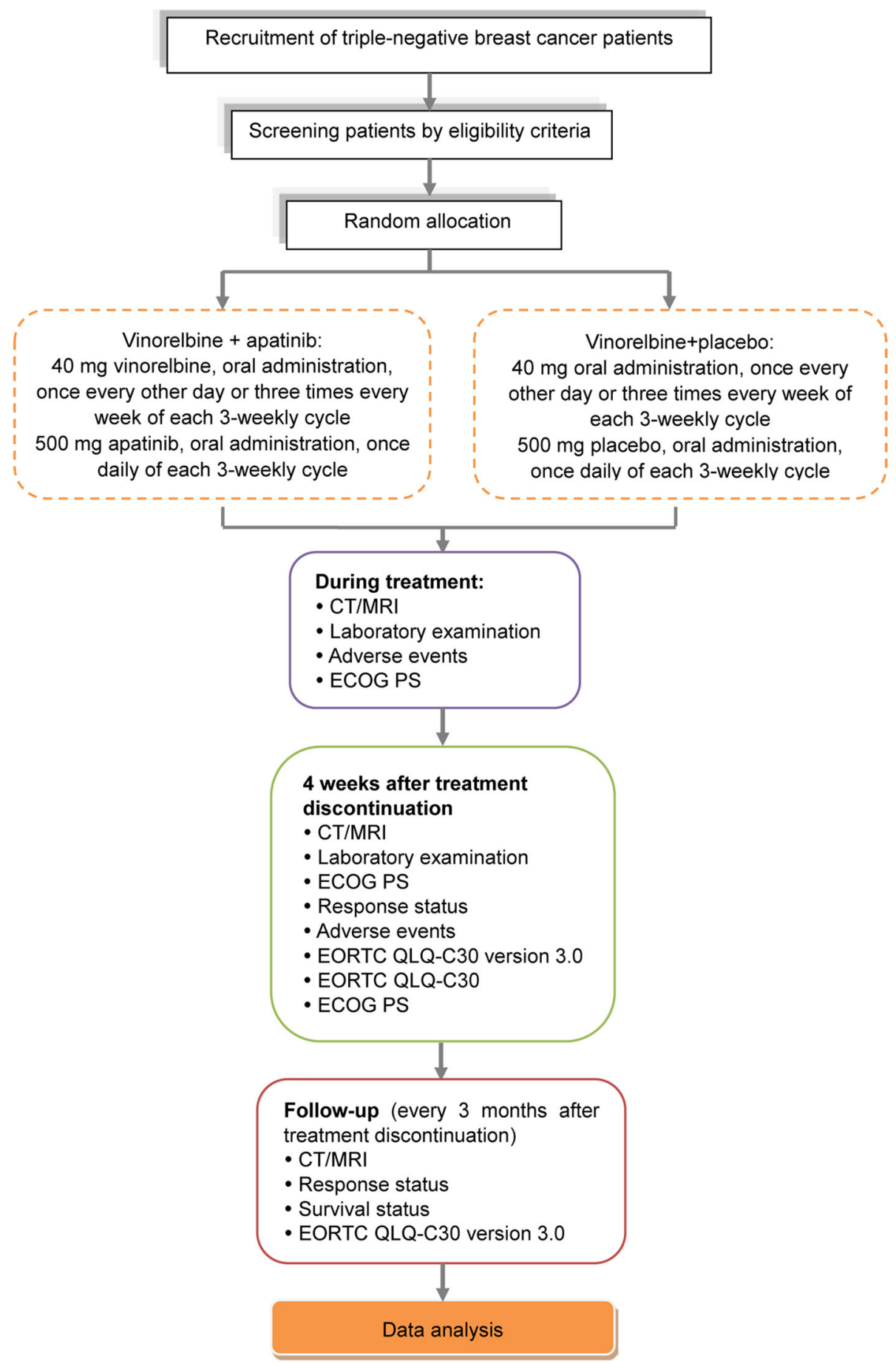

Fig. 2 Schedule of enrollment, interventions, and assessments. ECOG PS, Eastern Cooperative Oncology Group performance status; EORTC QLQC30, version 3, the European Organization for Research and Treatment of Cancer Quality of Life Questionnaire Core-30; CT, computed tomography; MRI, magnetic resonance imaging

assistants who will not be involved in the recruitment process. These envelopes will be secured in a doublelocked cabinet by another investigator who will not be involved in the trial.

\section{Blinding}

The patients, investigators, and the statistician will be unaware of the treatment allocation until the end of the trial. The Office of Data Quality will provide the 
randomization assignment list to the Jiangsu Hengrui Pharmaceutical Co., Ltd., China, which will provide the blinded capsules. Nurses who will not participate in the trial will dispense drugs to eligible patients based on their allocation sequence.

In the case of an emergency, the investigators can promptly determine the medication that the patients are receiving, to ensure timely and correct medical treatment. If unblinding is necessary, study staff will contact the Office of Data Quality.

\section{Drug administration}

Vinorelbine plus apatinib group: a $40 \mathrm{mg}$ vinorelbine tartrate soft capsule (brand name Navelbine, registration number H20140657; Pierre Fabre Medicament, Boulogne, France) is administered orally in the morning (at least $1 \mathrm{~h}$ before, or at least $1 \mathrm{~h}$ after meals), three times a week (Mondays, Wednesdays, and Fridays), for a continuous 21-day cycle. A $500 \mathrm{mg}$ apatinib mesylate tablet (brand name Aitan; state medical permission number. H20140103), is administered orally once a day for a continuous 21-day cycle.

Vinorelbine plus placebo group: oral administration of vinorelbine will be the same as in the vinorelbine plus apatinib group. In addition, the patients will be given oral placebo (starch as an ingredient). The placebo appearance, including shape, size, color and weight, taste, labeling, and packing is the same as that of the apatinib mesylate tablets.

The placebo and the apatinib will be manufactured by Jiangsu Hengrui Pharmaceutical Co., Ltd., China in accordance with the guidelines of Good Manufacturing Practice (Chinese Edition). The manufacturer will have no direct involvement in the study (apart from the drug manufacturing and delivery to the clinical trial centers). An assessment will be conducted at the end of every second cycle of the described administration protocol, until unacceptable toxicity or disease progression is observed.

\section{Dose adjustment}

Principle for dose adjustment: in the case of adverse events associated with apatinib, the dose will be adjusted first (Table 2). There are two dose levels for apatinib: (1) initial dose: $500 \mathrm{mg}$, once daily; (2) secondary dose: 250 $\mathrm{mg}$, once daily. Medication will be paused if the patients cannot recover from drug toxicity. The time for each pause and the cumulative time of overall pauses per cycle are limited to 1 week. There is a maximum of two pauses per cycle, to ensure the medication intensity in each patient. Patients not meeting the above criteria, or having a delay of the subsequent treatment cycle of at least 2 weeks, will be required to withdraw from the trial.

The dose of apatinib can be adjusted at any time during each dosing cycle. Once the dose is reduced, however, a subsequent increase to the previous level is not permitted. Only a single dose adjustment is allowed for each subject. After the dose is decreased to $250 \mathrm{mg}$, no further dose adjustments are permitted for any reason. However, pausing of medication administration will still be permitted.

When any conditions that meet the criteria for drug withdrawal are observed, administration of vinorelbine will be discontinued. If the patient meets the criteria for drug re-administration in the subsequent cycles, vinorelbine administration will be resumed, but the doses that are not taken during the withdrawal period will be omitted (Table 3).

\section{Concomitant medications}

Conventional medications will be given to address patient symptoms. These may include prophylactic antiemetics and treatment with granulocyte colony-stimulating factor (as indicated by the patient's hemogram). Hematopoietic growth factor support is permitted to avoid treatment interruption or delay. All symptomatic medications will be documented and detailed on a case report form.

\section{Assessment \\ Baseline evaluations (conducted within 2 weeks of the start of protocol therapy)}

We will collect baseline data as follows:

- Demographic data

- American Joint Committee on Cancer tumor diagnosis and staging

- Relevant clinical disease history (diagnosis and treatment)

- Concomitant medication

- Physical examination

- Vital signs

- ECOG-PS score

- Imaging (computed tomography (CT) or magnetic resonance imaging (MRI))

- Electrocardiogram

- Laboratory tests: routine blood test, liver and kidney functional electrolytes (including $\mathrm{K}^{+}, \mathrm{Na}^{+}, \mathrm{Cl}^{-}, \mathrm{Ca}^{2+}$, $\mathrm{Mg}^{2+}$ )

- Tumor markers: CA153, carcinoembryonic antigen (CEA)

- Pregnancy test (if necessary)

- The European Organization for Research and Treatment of Cancer Quality of Life Questionnaire Core-30 (EORTC QLQ-C30, version 3)

During treatment (conducted every 6 weeks (two cycles))

During treatment we will collect data on the following:

- Physical examination 
Table 2 Principle for the adjustment of apatinib dose

\begin{tabular}{|c|c|c|}
\hline $\begin{array}{l}\text { Classification of adverse } \\
\text { reactions }\end{array}$ & $\begin{array}{l}\mathrm{NCl}-\mathrm{CTC} \\
\text { level }\end{array}$ & Dose adjustment \\
\hline \multirow[t]{2}{*}{$\begin{array}{l}\text { Hematologic adverse } \\
\text { reactions }\end{array}$} & 3 & $\begin{array}{l}\text { Drug administration will be paused at level } 3 \text { and will be continued at the initial dose when the } \mathrm{NCl} \text { level is } \\
\text { restored to } \leq \text { level } 2 \text {. If } \mathrm{NCl} \geq \text { level } 3 \text { occurs again, drug administration at the secondary dose will be } \\
\text { continued }\end{array}$ \\
\hline & 4 & $\begin{array}{l}\text { Drug administration will be paused at level } 4 \text { and will be continued at the secondary dose when the } \mathrm{NCl} \text { is } \\
\leq \text { level } 2\end{array}$ \\
\hline \multirow[t]{2}{*}{$\begin{array}{l}\text { Non-hematologic adverse } \\
\text { reactions }\end{array}$} & 3 & $\begin{array}{l}\text { Drug administration will be paused at level } 3 \text { and will be continued at the initial dose when the } \mathrm{NCl} \text { is } \\
\text { restored to } \leq \text { level } 1 \text {. If the } \mathrm{NCl} \geq \text { level } 3 \text { occurs again, drug administration at the secondary dose will be } \\
\text { continued }\end{array}$ \\
\hline & 4 & $\begin{array}{l}\text { Drug administration will be paused at level } 4 \text { and will be continued at the secondary dose when the } \mathrm{NCl} \text { is } \\
\leq \text { level } 1\end{array}$ \\
\hline
\end{tabular}

Adverse reactions will be assessed using the National Cancer Institute Common Toxicity Criteria (NCl-CTC) Version $4^{30}$

- Vital signs

- ECOG-PS score

- Imaging test (CT or MRI)

- Laboratory tests: routine blood test, liver and kidney functional electrolytes (including $\mathrm{K}^{+}, \mathrm{Na}^{+}, \mathrm{Cl}^{-}, \mathrm{Ca}^{2+}$, $\mathrm{Mg}^{2+}$ )

- Tumor markers: CA153, CEA

- EORTC-QLQ-C30 version 3 score

- Adverse reactions, concomitant medications

\section{Follow up}

At 4 weeks after treatment discontinuation we will collect data on the following:

Table 3 Criteria for drug withdrawal and re-administration

\begin{tabular}{|c|c|}
\hline \multicolumn{2}{|l|}{ Drug withdrawal } \\
\hline Neutrophil & Level 3 or 4 \\
\hline Platelet & Level 3 or 4 \\
\hline Serum creatinine & $\begin{array}{l}1.5 \text { times over the upper limit of normal value (44- } \\
132 \mu \mathrm{M})\end{array}$ \\
\hline Infection & Infectious fever with temperature $>38^{\circ} \mathrm{C}$ \\
\hline $\begin{array}{l}\text { Diarrhea, mouth } \\
\text { ulcers }\end{array}$ & Level 3 or 4 \\
\hline Others & $\begin{array}{l}\text { When adverse reactions occur in addition to the } \\
\text { above, and the investigators cannot judge whether } \\
\text { drug administration can be continued or not, the } \\
\text { drug will be discontinued }\end{array}$ \\
\hline \multicolumn{2}{|c|}{ Drug re-administration } \\
\hline Neutrophil & $>1.0 \times 10^{9} / \mathrm{L}$ \\
\hline Platelet & $>50 \times 10^{9} / \mathrm{L}$ \\
\hline Serum creatinine & $<$ the upper limit of normal value $(44-132 \mu \mathrm{M})$ \\
\hline Infection & No infectious fever \\
\hline $\begin{array}{l}\text { Diarrhea, mouth } \\
\text { ulcers }\end{array}$ & $\leq$ Level 1 \\
\hline Others & $\begin{array}{l}\text { When adverse reactions leading to drug withdrawal } \\
\text { are alleviated or disappear, the administration can be } \\
\text { resumed as determined by the investigators }\end{array}$ \\
\hline
\end{tabular}

Drug withdrawal and re-administration will be assessed using the National Cancer Institute Common Toxicity Criteria (NCl-CTC) Version $4^{30}$
- Physical examination

- Vital signs

- ECOG-PS score

- Laboratory tests: routine blood test, liver and kidney functional electrolytes (including $\mathrm{K}^{+}, \mathrm{Na}^{+}, \mathrm{Cl}^{-}, \mathrm{Ca}^{2+}$, $\mathrm{Mg}^{2+}$ )

- Tumor markers: CA153, CEA

- EORTC-QLQ-C30 version 3 score

- Adverse reactions

- Concomitant medications (opioid analgesic consumption and new anticancer treatment)

Every 3 months after treatment discontinuation, until the patient dies or reaches study completion, we will collect data on the following:

- ECOG-PS score

- New anticancer treatment(s)

- Disease progression

- Survival status

\section{Outcomes}

Primary outcome

PFS refers to the length of time from randomization and group allocation to any recorded tumor progression (including tumor recurrence, presence of new lesions, tumor treatment, and the use of other systemic or targeted anti-tumor therapies) or death (due to any cause). If the patient has several indicators that can be judged as progression of disease, the PFS analysis will be performed based on the indicator that first emerged. For patients with no tumor progression and who are still alive by the end of the study, the PFS time recorded at the last follow up will be censored. Tumor conditions during the treatment and follow-up periods will be evaluated in accordance with the RECIST version 1.1 criteria.

\section{Secondary outcomes}

The secondary outcomes are as follows: 
1. OS refers to the length of time from randomization to mortality from any cause. In cases where no information on mortality is available in the clinical database, the last date on which the patient is known to have survived is used as the cut-off point.

2. The DCR indicates the percentage of patients who have achieved CR, partial remission (PR), and disease stabilization for over 4 weeks continuous, accounting for all the subjects with evaluable efficacy.

3. The ORR is the proportion of patients who achieve $\mathrm{CR}$ or $\mathrm{PR}([\mathrm{CR}+\mathrm{PR}] /$ total number of cases $x$ $100 \%)$, as assessed by the RECIST v1.1 [30].

4. Adverse events at levels 3 and 4: patients with adverse events at levels 3 and 4 will be assessed according to the National Cancer Institute Common Toxicity Criteria (NCI-CTC) Version 4.0 [32].

\section{Other measures}

Other measures will be performed as follows:

1. Quality of life will be assessed using the EORTC QLQ-C30 version 3.0 [33]. The scores will be averaged and transformed linearly to obtain a range of scores, from 0 to 100, with higher scores indicating better quality of life.

2. General health status is assessed using the ECOGPS scale [34]. The scale divides the patient's activity status into $0-5$ levels. A higher level indicates a worse physical status.

3. Laboratory examination: (1) hematology assessments: hemoglobin, white blood cell count, neutrophil count, and platelet count; (2) blood biochemical tests: total bilirubin, ALT, AST, alkaline phosphatase, serum creatinine, total protein, $\mathrm{Na}^{+}, \mathrm{K}^{+}, \mathrm{Mg}^{2+}, \mathrm{Cl}^{-}, \mathrm{Ca}^{2+}$, urea, and pregnancy test (if applicable); and (3) tumor marker detection: CA153 and CEA.

\section{Adverse events}

All adverse events will be recorded appropriately in a case report form and assessed by the investigators according to the NCI-CTC version 4.0 [32]. If the level of ALT or AST is $\geq 3 \times U L N$, or total bilirubin $\geq 2 \times U L N$, a serious adverse event (SAE) report may be necessary. The investigators must promptly determine whether the patient meets Hy's Law (drug-induced liver injury (DILI)), without delay.

The investigators will assess the causal relationship between adverse events and target drugs. The decisive factor in the assessment is the temporal correlation between the adverse event and target drug. All deaths during the intervention period, and during the last follow-up period ( 30 days after the last dose) and the period up to documented disease progression (whichever occurs later) will be reported.

The investigator is obliged to immediately (within $24 \mathrm{~h}$ ) call, fax, or email information on any serious or medically significant clinical adverse events or laboratory abnormalities during the study period, to the Adverse Drug Reaction Monitoring Center, the Sponsor, and the Ethics Committee. This applies regardless of group allocation. Optimal supportive therapy will be provided in cases of hematological toxicity, nonhemotoxic diarrhea, liver toxicity, and peripheral neurotoxicity.

\section{Criteria for re-administration/cycle delay}

Patients who meet all of the following criteria can receive the planned treatment:

- Absolute neutrophil count (ANC) $>1500 / \mathrm{mm}^{3}$

- Platelets $>100,000 / \mathrm{mm}^{3}$

- Treatment related to non-hematologic toxicity has been eliminated at baseline or is at a level $\leq 1$ (except for level-2 alopecia or level-2 fatigue)

If the patient cannot meet these criteria, the planned treatment will be delayed and the patient's condition will be re-evaluated at least once a week.

Additional criteria for re-administration/cycle delay are as follows:

- The medication on the 8th day of each cycle cannot be delayed for longer than 1 week, otherwise, the patient will be withdrawn from the study. The time of medication administration in the next cycle will not change.

- In the case of failure to recover from treatmentrelated toxicity to baseline or level 1 (except level 2 and level-2 fatigue) within 3 weeks as scheduled (i.e., the start of each new cycle is delayed for over 21 days as compared with the scheduled time), the patient will be withdrawn from the trial.

- Patients can continue to use the drug, with the consent of the Sponsor, if the treatment is deemed to be effective.

\section{Participant withdrawal}

Patients will be withdrawn from the study if they (1) withdraw their informed consent; (2) request to withdraw from the trial; or (3) decline to continue treatment or follow up. All source data and source files related to all withdrawn participants will be retained. The time and cause of withdrawal will be recorded on the case report form in detail. 


\section{Monitoring}

Progression of the trial, adverse events, and data quality will be monitored by an Independent Data (and safety) Monitoring Board (IDMB), which is independent of the trial Sponsor. The IDMB will be responsible for reporting the security data in the trial to the primary investigator. The primary investigator will submit a list of all suspected SAEs to the Independent Ethics Committee (IEC), as well as a summary of all reported SAEs every 6 months.

\section{Audits}

An inspector will review the incoming data monthly and generate a data query if necessary. The inspector will review whether each electronic case report form is completed accurately. All discrepancies in the electronic case report form will be corrected by the investigator or authorized personnel in an appropriate manner.

\section{Data management}

Data entry and management are the responsibility of an independent data administrator, who will use the EpiData 3.1 software (The EpiData Association, Denmark, Europe). All data will be independently inputted and proofread by two data administrators, to ensure accuracy. The data administrators will list the questions in the case report form in the data request queue (DRQ), and the investigator will respond as soon as possible. The data administrators will then modify, confirm, and enter the data according to the investigator's responses. Another DRQ can be submitted if necessary. All original files will be kept in accordance with the principles of Chinese Good Clinical Practice, and clinical data will be kept by the investigators for 5 years (starting from the end of the clinical trial). All clinical data pertaining to the trial will be the property of the Sponsor, and the investigators will have no right to disclose these data to a third party without written approval by the Sponsor.

\section{Sample size}

The survival time of the patients will be compared between the two groups by the log-rank test, using PASS Sample Size Software 11.0 (NCSS LLC, Kaysville, Utah, USA) [35]. Based on previous experience [36] and pilot study results, the mPFS was estimated to be 4.1 months in the vinorelbine monotherapy group and 6.7 months in the vinorelbine plus apatinib group (hazard ratio $(\mathrm{HR})=$ 0.61 ). The recruitment time is expected to be 26 months (from the beginning of recruitment to the enrollment of the last patient) and a 15-month follow-up time is planned. Assuming a dropout rate of $10 \%$ across both groups, power of $80 \%$, and two-sided significance of $\alpha=$ 0.05 , a sample size of 238 patients (119 in each intervention group) will be required.

\section{Statistical analysis}

The primary analysis will be based on the intent-to-treat (ITT) principle (i.e. all patients will be analyzed according to their allocated treatment group). Missing primary endpoint data will be imputed conservatively. We will consider a sensitivity analysis using complete case, i.e. not imputing missing values, to assess if there is a difference in results. No interim analysis will be performed.

A statistician will perform the statistical analyses using SPSS 22.0 software (IBM, Armonk, NY, USA). Continuous variables will be summarized as the mean, standard deviation, median, minimum, and maximum. Means and standard deviations will be reported if the variable is normally distributed; if the data are skewed, medians and interquartile ranges will be used. Categorical variables will be expressed as numbers and percentages.

The baseline data will be summarized accordingly, depending on the data type (continuous, categorical). Categorical variables will be compared between groups using Pearson's chi-square test. Continuous variables will be compared between groups using the two-sample $t$ test (normally distributed data) or Mann-Whitney $\mathrm{U}$ test (non-normally distributed data). All statistical analyses will be performed based on a two-sided test. A $P$ value $\leq 0.05$ will be considered statistically significant, and the $95 \%$ CI will be calculated.

Survival data (PFS and OS) will be estimated using the Kaplan-Meier method. Differences between grouped survival profiles will be assessed by the log-rank test. Factors influencing survival (i.e., age, tumor, node, metastasis (TNM) staging, tumor differentiation status, lymph node metastasis, and chemotherapy cycles) will be analyzed using Cox proportional hazard regression analysis. Results will be expressed as HRs and 95\% CIs.

\section{Quality control}

The clinical research unit will satisfy the requisite clinical research conditions for drug research, as determined by the National Medical Products Administration of China. Investigators will be clinically trained physicians who work under the direction of a senior physician. Clinical wards will be standardized to ensure that rescue equipment is fully functional. Medications will be administered by professional caregivers, and patient compliance will be ensured by learning about the medication. The standard operating rules of clinical trials will be followed and implemented in the research center. All clinical procedures will be supervised, and the complete and correct reporting of all data will be confirmed by comparing case report forms and the source data. In the event that an SAE occurs, it will be promptly reported to each research unit and, if necessary, the trial will be temporarily discontinued. 


\section{Ethics and dissemination \\ Ethics and informed consent}

The trial will be conducted in accordance with Good Clinical Practice guidelines, the guiding principles of the Declaration of Helsinki, and applicable local laws and regulations. The study protocol was approved by the IEC of the Liaoning Provincial Cancer Hospital in October 17, 2018 (approval No. 20180948-2) (Additional file 2) and the trial has been registered at ClinicalTrials.gov (identifier: NCT03932526). This research plan refers to protocol V2.0.

Written informed consent will be given by each patient prior to participation in the trial. The investigator will inform the patients that participation in the study is voluntary, and that they can withdraw at any time. Patients will be informed that the investigator will maintain their records over the long-term follow-up period, and that their records may be viewed by relevant management officers, within the limits of relevant laws and regulations. The privacy of all patients will be protected.

\section{Dissemination}

The final research results will be disseminated through publications in peer-reviewed academic journals and at international academic conferences.

\section{Protocol amendments}

All amendments to the protocol will be signed and dated by the Department of Breast Medicine, the Liaoning Provincial Cancer Hospital, China, and approved by the IEC before release. Any protocol deviation that may occur during the study will be promptly managed by the investigator. The protocol deviation, including reason(s) for its occurrence, will be documented in the case report form and the original case report, which will be retained in the research unit by the Sponsor.

\section{Principle of confidentiality}

Collection and use of patient data will comply with relevant laws and regulations that protect the subjects' privacy, and full confidentiality will be maintained. The participants have the right to obtain their personal data through the investigator, and to modify any errors or incomplete data. No personal information will be disclosed to unauthorized parties. The Sponsor will maintain the confidentiality of all personal data throughout the study period.

\section{Compensation}

The drugs used in this trial will be provided by the pharmaceutical company; the company has no role in the study design; collection, management, analysis, and interpretation of data; writing of the report; or the decision to submit the report for publication.
Each patient having provincial, municipal, remote, or new rural cooperation medical insurance will be subsidized with RMB 600 yuan ( 85.5 USD) after completing one chemotherapy cycle. Self-paying patients will be given the subsequent cycle of chemotherapy free of charge (chemotherapy drugs only) after the initial cycle of chemotherapy.

Compensation mechanism: the specific compensation standards and methods will be clarified before the trial, and the Sponsor will provide clinical trial insurance for each subject. Treatment costs for drug-related adverse events and corresponding economic compensation will be undertaken by the Sponsor.

\section{Discussion}

The anti-tumor effect of conventional chemotherapy relies on a single maximum tolerated dose. Despite its wide use, traditional scheduling of chemotherapy cycles is not convenient for patients, as frequent hospital visits for infusion and in-patient admission are required. To reduce the side effects of chemotherapy, treatment cycles are separated by longer intervals. This prospective randomized controlled trial, conducted in Liaoning Province of Northeast China, will be the first to analyze the efficacy of apatinib-targeted therapy, combined with vinorelbine chemotherapy, in treating patients with recurrent or metastatic TNBC, who have previously received anthracyclines and taxanes. Some limitations should be acknowledged in the current study protocol. As all subjects are limited to the northern Chinese population, the study results may not be generalizable to other patient populations. Furthermore, the sample size is relatively small, and this is due to limitations in staffing and funding.

Based on the data from this trial, we hope to identify an optimal treatment regimen that is suitable for female patients with TNBC in Northeast China, who have been treated with anthracyclines and taxanes.

\section{Trial status}

The trial was registered at ClinicalTrials.gov (identifier: NCT03932526) on 30 April 2019. Patient recruitment will begin in June 2019, and end in August 2022. Analysis of the primary outcome measure will be completed in December 2022. The study will end in June 2023. This research plan refers to protocol V2.0.

\section{Supplementary information}

Supplementary information accompanies this paper at https://doi.org/10. 1186/s13063-020-04342-x.

Additional file 1. SPIRIT checklist.

Additional file 2. Ethics committee approval. 


\section{Abbreviations}

AJCC: American Joint Committee on Cancer; ALT: Alanine aminotransferase: ANC: Absolute neutrophil count; AST: Aspartate aminotransferase; CEA: Carcinoembryonic antigen; Cl: Confidence interval; CR: Complete response; CT: Computed tomography; DCR: Disease control rate; DILI: Druginduced liver injury; DRQ: Data request queue; ECOG: Eastern Cooperative Oncology Group; ECOG-PS: Eastern Cooperative Oncology Group performance status; EDC: Electronic data capture system; EORTC QLQ-C30, version 3: European Organization for Research and Treatment of Cancer Quality of Life Questionnaire Core-30; ER: Estrogen receptors; HER-2: Human epidermal growth factor receptor 2; IDMB: Independent Data Monitoring Board; IEC: Independent Ethics Committee; mOS: Mean overall survival; mPFS: Mean progression-free survival; MRI: Magnetic resonance imaging; mTTP: Median time to progression; NCI-CTC: National Cancer Institute Common Toxicity Criteria; ORR: Objective response rate; OS: Overall survival; PR: Progesterone receptors; RECIST: Response Evaluation Criteria in Solid Tumors; SAEs: Serious adverse events; SPIRIT: Standard Protocol Items Recommendations for Interventional Trials; TNBC: Triple-negative breast cancer; TTP: Time to progression; ULN: Upper limit of normal; VEGF: Vascular endothelial growth factor; VEGFR: Vascular endothelial growth factor receptor

\section{Funding statement}

The drugs used in this trial will be provided by the pharmaceutical company directly, and the Sponsor will provide clinical trial insurance for each participant. The company has no role in the study design; collection, management, analysis, and interpretation of data; writing of the report; or the decision to submit the report for publication. Treatment costs for drugrelated adverse events and corresponding economic compensation will be undertaken by the Sponsor.

\section{Authors' contributions}

TS and SW conceived the study and participated in its design and coordination. SW drafted and wrote the manuscript. LZ and HL participated in the design of the study and performed the statistical analysis. JX and CJ participated in the study design and coordination, and helped draft the manuscript. All authors read, revised and approved the final manuscript.

\section{Availability of data and materials}

The results of this study will be disseminated via peer-reviewed publications and conference presentations. No data are available at the moment.

\section{Ethics approval and consent to participate}

The trial will be conducted in accordance with the guiding principles of the Declaration of Helsinki. The study protocol was approved by the Ethics Committee of the Liaoning Provincial Cancer Hospital (approval number 20180948-2) in October 2018. All patients will provide written informed consent prior to their participation in the trial.

\section{Consent for publication}

Not applicable.

\section{Competing interests}

The authors declare that they have no competing interests.

Received: 18 July 2019 Accepted: 24 April 2020

Published online: 24 May 2020

\section{References}

1. Magrath I. Cancer in low-and middle-income countries. Health. 2010;20:58-68.

2. Breast cancer incidence and mortality worldwide in 2008. GLOBOCAN 2008; International Agency for Research on Cancer, Lyon, France. Available from: http://globocan.iarc.fr/. Accessed 26 Jan 2011.

3. Zhao JT, Liu Y, Wang KR. Progress in nanotherapy of triple negative breast cancer. Chin J New Drugs Clin Remed. 2016;35:229-33.

4. Zhang JB, Shi YH, Jia Y, et al. Progress in the treatment of triple negative breast cancer. Cancer. 2017;37:788-94.

5. Lehmann BD, Bauer JA, Chen X, Sanders ME, Chakravarthy AB, Shyr Y, et al. Identification of human triple-negative breast cancer subtypes and preclinical models for selection of targeted therapies. J Clin Invest. 2011;121: 2750-67.
6. Greenberg PA, Hortobagyi GN, Smith TL, Ziegler LD, Frye DK, Buzdar AU Long-term follow-up of patients with complete remission following combination chemotherapy for metastatic breast cancer. J Clin Oncol. 1996; 14:2197-205.

7. National Comprehensive Cancer Network (NCCN) 2010 guidelines: Breast cancer. Available from: http://www.nccn.org/professionals/physician_gls/f_ guidelines.asp.

8. O'Shaughnessy J. Extending survival with chemotherapy in metastatic breast cancer. Oncologist. 2005;10(Suppl 3):20-9.

9. Schmid P, Cortés J, Dent R, Pusztai L, McArthur HL, Kuemmel S, et al. KEYNOTE-522: Phase III study of pembrolizumab (pembro) 1 chemotherapy (chemo) vs placebo (pbo) 1 chemo as neoadjuvant treatment, followed by pembro vs pbo as adjuvant treatment for early triple-negative breast cancer (TNBC). Ann Oncol. 2019;30(Supp_5):mdz394-003.

10. Cortés J, Lipatov O, Im SA, Gonçalves A, Lee KS, Schmid P, et al. KEYNOTE119: Phase III study of pembrolizumab (pembro) versus single-agent chemotherapy (chemo) for metastatic triple negative breast cancer (mTNBC). Ann Oncol. 2019;30(Supp_5):mdz394.010.

11. Emens LA, Adams S, Loi S, Schneeweiss A, Rugo HS, Winer EP, et al. IMpassion130: a phase III randomized trial of atezolizumab with nabpaclitaxel for first-line treatment of patients with metastatic triple-negative breast cancer (mTNBC). J Clin Oncol. 2016;15(Supp):TPS1104.

12. Schmid P, Adams S, Rugo HS, Schneeweiss A, Barrios $\mathrm{CH}$, Iwata $\mathrm{H}$, et al. IMpassion130: updated overall survival (OS) from a global, randomized, double-blind, placebo-controlled, phase III study of atezolizumab (atezo) + nab-paclitaxel (nP) in previously untreated locally advanced or metastatic triple-negative breast cancer (mTNBC). J Clin Oncol. 2019;15(Supp):1003.

13. Hu X, Zhang J, Xu B, Jiang Z, Ragaz J, Tong Z, et al. Multicenter phase II study of apatinib, a novel VEGFR inhibitor in heavily pretreated patients with metastatic triple-negative breast cancer. Int J Cancer. 2014;135:1961-9.

14. Hu X, Cao J, Hu W, Wu C, Pan Y, Cai L, et al. Multicenter phase II study of apatinib in non-triple-negative metastatic breast cancer. BMC Cancer. 2014; 14:820.

15. Li J, Qin S, Xu J, Guo W, Xiong J, Bai Y, et al. Apatinib for chemotherapyrefractory advanced metastatic gastric cancer: results from a randomized, placebo-controlled, parallel-arm, phase II trial. J Clin Oncol. 2013;31:3219-25.

16. Ghosn M, Kattan J, Farhat F, Younes F, Gasmi J. Phase II trial of capecitabine and vinorelbine as first-line chemotherapy for metastatic breast cancer patients. Anticancer Res. 2006;26:2451-6.

17. Sano M, Tokuda Y, Noguchi S, Aogi K, Saeki T, Tabei T, et al. A phase-I clinical study of a combination therapy of vinorelbine and capecitabine in patients with advanced/recurrent breast cancer. Gan To Kagaku Ryoho. 2006;33:1091-7.

18. Sun YL, Lu ZX, Wang LB. Vinorelbine combined with capecitabine in the treatment of advanced and metastatic breast cancer. J Prac Oncol. 2005;19: 9-11.

19. Wang JB, Yang $Y$, Wang $Z S$, Wang $M X$, Zheng RS. Clinical efficacy and safety of vinorelbine or gemcitabine combined with cisplatin in the treatment of metastatic triple-negative breast cancer. Chin J Clin Pharmacol. 2016;32:24-6.

20. Rodler ET, Kurland BF, Griffin M, Gralow JR, Porter P, Yeh RF, et al. Phase I study of veliparib (ABT-888) combined with cisplatin and vinorelbine in advanced triple-negative breast cancer and/or BRCA mutation-associated breast cancer. Clin Cancer Res. 2016;22:2855-64.

21. Zhang J, Wang L, Wang Z, Hu X, Wang B, Cao J, et al. A phase II trial of biweekly vinorelbine and oxaliplatin in second- or third-line metastatic triple-negative breast cancer. Cancer Biol Ther. 2015;16:225-32.

22. Li YH, Zhou Y, Wang YW, Tong L, Jiang RX, Xiao L, et al. Comparison of apatinib and capecitabine (Xeloda) with capecitabine (Xeloda) in advanced triple-negative breast cancer as third-line therapy: a retrospective study. Medicine. 2018;97:e12222.

23. Wang J, Zheng R, Wang Z, Yang Y, Wang M, Zou W. Efficacy and safety of vinorelbine plus cisplatin vs. gemcitabine plus cisplatin for treatment of metastatic triple-negative breast cancer after failure with anthracyclines and taxanes. Med Sci Monit. 2017;23:4657-64.

24. Du F, Yuan P, Luo Y, Wang J, Ma F, Cai R, et al. Efficacy and toxicity of vinorelbine (NVB)-based regimens in patients with metastatic triple negative breast cancer (mTNBC) pretreated with anthracyclines and taxanes. Zhonghua Zhong Liu Za Zhi. 2015;37:788-92.

25. Li M, Fan Y, Li Q, Zhang P, Yuan P, Ma F, et al. Vinorelbine plus platinum in patients with metastatic triple negative breast cancer and prior anthracycline and taxane treatment. Medicine. 2015;94:e1928. 
26. Hu T, Liu C, Li Q, Xiong J, Ma Y, Wu G, Zhao Y. Apatinib + CPT-11 + S-1 for treatment of refractory brain metastases in patient with triple-negative breast cancer: case report and literature review. Medicine. 2018;97:e0349.

27. Zhou N, Liu C, Hou H, Zhang C, Liu D, Wang G, et al. Response to apatinib in chemotherapy-failed advanced spindle cell breast carcinoma. Oncotarget. 2016;7:72373-9.

28. CONSORT Group. CONSORT: Consolidated standards of reporting trials. 2008.

29. Chan AW, Tetzlaff JM, Altman DG, Laupacis A, Gøtzsche PC, Krleža-Jerić K, et al. SPIRIT 2013 statement: defining standard protocol items for clinical trials. Ann Intern Med. 2013;158:200-7.

30. Eisenhauer EA, Therasse P, Bogaerts J, Schwartz LH, Sargent D, Ford R, et al. New response evaluation criteria in solid tumours: revised RECIST guideline (version 1.1). Eur J Cancer. 2009;45:228-47.

31. Editorial Group of the Breast Cancer HER-2 Detection Guide (2014 Edition) Breast cancer HER-2 detection guide (2014 Edition). Chin J Pathol. 2014;43: 262-7.

32. US Department of Health and Human Services, National Cancer Institute. Common terminology criteria for adverse events (CTCAE) Version 4.0. Bethesda: National Institutes of Health/National Cancer Institute; 2009.

33. Zhao H, Kanda K. Testing psychometric properties of the standard Chinese version of the European Organization for Research and Treatment of Cancer Quality of Life Core Questionnaire 30 (EORTC QLQ-C30). J Epidemiol. 2004; 14:193-203.

34. Shvarts O, Lam JS, Kim HL, Han KR, Figlin R, Belldegrun A. Eastern Cooperative Oncology Group performance status predicts bone metastasis in patients presenting with renal cell carcinoma: implication for preoperative bone scans. J Urol. 2004;172:867-70.

35. Edward L. Sample sizes based on the log-rank statistic in complex clinical trials. Biometrics. 1988;44:229-41.

36. Wang XR, Wang X, Shi YH, Wang C, Tong ZS. Clinical efficacy of apatinib in treating refractory triple-negative advanced breast cancer. Chin Cancer Clin. 2017:44:769-72.

\section{Publisher's Note}

Springer Nature remains neutral with regard to jurisdictional claims in published maps and institutional affiliations.

Ready to submit your research? Choose BMC and benefit from:

- fast, convenient online submission

- thorough peer review by experienced researchers in your field

- rapid publication on acceptance

- support for research data, including large and complex data types

- gold Open Access which fosters wider collaboration and increased citations

- maximum visibility for your research: over $100 \mathrm{M}$ website views per year

At $\mathrm{BMC}$, research is always in progress.

Learn more biomedcentral.com/submissions 